\title{
ESCOLHA CURRICULAR COMO PROBLEMA FILOSÓFICO: UMA ANÁLISE CRÍTICA DAS DIRETRIZES CURRICULARES NACIONAIS DO ENSINO MÉDIO
}

\author{
JOSÉ SÉRGIO FONSECA DE CARVALHO ${ }^{*}$ \\ ORCID: https://orcid.org/0000-0002-0074-0872
}

Não se deve exagerar sobre o presente, pois se
a nós ele se apresenta
tão difícil é porque, dentre outras coisas,
nos cabe vivê-lo.
Maria Zambrano

RESUMO: O currículo do ensino médio tem sido objeto de intensa polêmica. As Diretrizes Curriculares Nacionais para o Ensino Médio (2013) figuram como um dispositivo normativo cuja aspiração é oferecer aos sistemas de ensino um "conjunto de definições doutrinárias sobre princípios, fundamentos e procedimentos [...] que orientarão as escolas brasileiras [...] na organização, na articulação [...] e na avaliação de suas propostas pedagógicas". Dentre os temas abordados pelo documento, voltamos nossa atenção para aquele que, em sua densidade, figura como uma fonte inesgotável de tensões e problemas: os princípios e critérios de escolha de e "programas de estudo" para esse segmento da escolaridade. Mais especificamente interessa-nos analisar criticamente, em diálogo com o pensamento político e educacional de Arendt e Rancière, dois aspectos centrais dessa discussão empreendida pelas DCN: a suposta centralidade dos jovens nos processos educativos e a natureza dos compromissos da escola para com a superação das desigualdades socioeconômicas.

Palavras-chaves: Ensino Médio. Filosofia da Educação. Arendt. Rancière.

CURRICULAR CHOICE AS A PHILOSOPHICAL PROBLEM: A CRITICAL ANALYSIS OF NATIONAL CURRICULAR GUIDELINES FOR MIDDLE SCHOOL

ABSTRACT: The aims and identity of high school curriculum have become object of intense controversy. Brazilian National Curricular Guideline for Secondary Education (DCN, Brazil, 2013) is an important normative device

'Universidade de São Paulo, Faculdade de Educação, São Paulo, SP, Brasil.

"Professor Titular de Filosofia da Educação da FEUSP. Coordenador do Grupo de Estudos em Educação e Pensamento Contemporâneo (GEEPC). E-mail:<jsfcusp@usp.br > . 
whose aim is to offer "set of doctrinal definitions on principles, foundations and procedures.... which shall guide the schools [...] in their organization and articulation of pedagogical projects". Among various issues addressed by the document, we chose to turn our attention to the one that, in its density, figures as an inexhaustible source of tensions and problems: the principles and criteria for curricular choices. More specifically, we are interested in analyzing critically, in dialogue with Arendt's and Rancière's political and educational thought, two central aspects of this discussion undertaken by the DCN: the supposed centrality of youngsters in educational processes and the nature of the school's commitments to the overcoming of socioeconomic inequalities.

Keywords: High School Curriculum, Philosophy of Education, Arendt, Rancière.

\section{APRESENTAC̣̃̃O}

Os objetivos, a identidade e o currículo do ensino médio têm figurado como objeto de intensa polêmica nos últimos anos. Dentre as medidas propostas para reformá-lo e induzir melhorias em suas práticas educativas, merecem destaque o Parecer 5/2011 e a Resolução 2/2012 do Conselho Nacional de Educação. Ambos integram, desde então, as Diretrizes Curriculares Nacionais para a Educação Básica (DCN,2013), um documento complexo cujos objetivos abarcam desde a regulamentação dos sistemas de ensino até questões pontuais ligadas à formação dos profissionais de educação.

$\mathrm{Na}$ qualidade de dispositivo normativo da mais alta instância consultiva e deliberativa da educação nacional, as DCN oferecem uma interpretação operativa dos princípios e diretrizes gerais da Educação consignados em diplomas legais, como a Constituição Federal (Brasil, 1988) e a Lei de Diretrizes e Bases da Educação Nacional (Brasil,1996). Seu propósito é oferecer aos sistemas educacionais e a seus profissionais um "conjunto de definições doutrinárias sobre princípios, fundamentos e procedimentos na Educação Básica [...] que orientarão as escolas brasileiras [...] na organização, na articulação [...] e na avaliação de suas propostas pedagógicas", ${ }^{1}$ inclusive no que concerne aos princípios e critérios de escolha de "matrizes curriculares" e "programas de estudo" para esse segmento final da educação básica.

É precisamente para este último aspecto específico - e a partir de uma perspectiva vinculada à filosofia contemporânea - que se volta a presente reflexão. Sua intenção não é propor uma avaliação global das DCN como um documento de indução de políticas públicas. 
Trata-se, antes, de uma tarefa bem mais modesta e circunscrita: a de tecer um diálogo crítico com um conjunto de problemas ${ }^{3}$ que afloram de sua leitura e com as tensões que emergem do fato de que, como um documento produzido por um órgão colegiado cujas decisões respondem a uma diversidade de forças e movimentos sociais, seus pressupostos e princípios acabam por oferecer um panorama significativo de consensos e conflitos recorrentes nos debates educacionais contemporâneos acerca do tema das escolhas curriculares.

Mas, antes mesmo de apresentar um esboço dos problemas que mobilizam nossa atenção, vale a pena elucidar - ainda que de forma sumária - o significado que atribuímos à noção de "crítica" que caracteriza a natureza do diálogo que estabeleceremos com o documento do CNE. Trata-se de uma cautela importante, uma vez que seu uso indiscriminado transformou essa noção - e o adjetivo a ela vinculado - em arma retórica prestigiosa, mas de escasso potencial elucidativo, quando reduzida a qualquer sorte de oposição a uma tese ou princípio.

É evidente que o sentido que aqui lhe emprestamos não se opõe frontalmente à noção de um embate discursivo, mas a ela não se limita. Recorrer à noção de "crítica" em um contexto de escrita filosófica remete, necessariamente, a uma sólida tradição de pensamento cujo ponto de referência poderia ser situado - não sem algum grau de arbitrariedade - no espírito do Iluminismo ou do Esclarecimento (Aufklärung) e, em especial, na obra kantiana. Em uma importante nota acrescida ao Prefácio de sua Crítica da Razão Pura, Kant assevera:

A nossa época é a época da crítica, à qual tudo tem de submeter-se. A religião, pela sua santidade e a legislação, pela sua majestade, querem igualmente subtrair-se a ela. Mas então suscitam contra elas justificadas suspeitas e não podem aspirar ao sincero respeito, que a razão só concede a quem pode sustentar seu livre e público exame (Kant, 1989, p.5 grifo nosso). ${ }^{4}$

Ora, a vinculação que Kant postula existir entre o elemento central de sua obra - a crítica - e o contexto histórico e intelectual em meio ao qual ela surge já indica que não se trata de um esforço pessoal e isolado de um pensador, mas de uma "atitude intelectual" que se apresenta como signo de uma era. A crítica se forja, em sua tradição iluminista, como uma forma peculiar de diálogo que o Esclarecimento estabelece com um legado de ideias, teorias e representações que recebe do passado. Um diálogo que almeja submeter ao "tribunal da razão" uma herança cultural que considera impregnada de preconceitos e crenças infundadas, mas que não poupa sequer o próprio domínio do discurso racional, já que também o toma como um de seus objetos centrais de investigação. 
Nesse sentido, a noção de "crítica" ultrapassa - ainda que a incorpore - a mera negatividade expressa na rejeição das doutrinas e crenças que o Esclarecimento herda do passado e submete a um exame público. Ela se configura, antes, como uma disposição intelectual específica: a de submeter os assuntos humanos a um escrutínio sistemático no âmbito de seu uso público, ou seja, daquele que qualquer homem dela faz em face de um auditório, real ou virtual, de interlocutores. ${ }^{5}$

Por essa razão, para Kant (1987), o que caracteriza a crítica não são os resultados que ela enuncia, mas a atitude que a move: essa disposição incessante para submeter toda a sorte de produções discursivas a um exame público, visando o debate acerca da verdade de suas teses e da legitimidade de suas proposições. Assim, a autonomia do pensamento e do juízo crítico - ou seja, a maioridade do homem - não resultará, para Kant (1987), de um esforço intelectual solitário, mas do cultivo de um debate livre e público:

É difícil, portanto, para um homem em particular desvencilhar-se da menoridade que para ele se tornou quase uma natureza [...]. São muito poucos aqueles que conseguiram, pela transformação do próprio espírito, emergir da menoridade [...]. Que, porém, um público se esclareça [aufkläre] a si mesmo é perfeitamente possível; mais do que isso, se lhe for dada a liberdade, é quase inevitável. Pois encontrar-se-ão sempre alguns indivíduos capazes de pensamento próprio [...] que, depois de terem sacudidos de si mesmos o jugo da menoridade, espalharão em redor de si o espírito de uma avaliação racional do próprio valor e da vocação de cada homem em pensar por si mesmo. (Kant, 1987, p.102.) ${ }^{6}$

Muito embora o pensamento crítico - a faculdade de cada homem pensar por si mesmo - só se realize a partir da atividade de um sujeito singular, sua razão de ser e a condição para seu florescimento são, respectivamente, a comunicabilidade e a pluralidade, como ressalta Arendt em suas Lições sobre a filosofia política de Kant. Ainda que a liberdade de pensamento implique o direito individual à autonomia do juízo, sua plena realização exige a comunicabilidade, ou seja, a submissão do pensamento a um exame livre e aberto em face de uma "comunidade de seres humanos aos quais ele [aquele que pensa autonomamente] se dirige, que o escuta e aos quais ele pode escutar" (Arendt, 1992, p.90)..$^{7}$ Por essa razão, a liberdade de pensamento - e a noção de "crítica" a ela vinculada - implicam o compromisso público para com o exame reiterado das bases sobre as quais são construídas crenças, representações, normas e conhecimentos que caracterizam uma época e seu modo de vida. Sua relevância é, pois, a um só tempo epistemológica e política, pois aponta para a pluralidade como condição da vida pública. 
A leitura arendtiana de Kant (1992) assemelha-se, nesse aspecto, às reflexões que Foucault (1990) tecerá uma década depois, vinculando a noção de "crítica" à forma pela qual o Esclarecimento se relaciona não só com o legado que recebeu do passado, mas com as questões de seu presente e com suas expectativas em relação ao futuro. É, pois, a partir de uma perspectiva que considera a dimensão histórica inerente ao projeto do Esclarecimento que a "crítica" será por ele identificada como uma virtude ética e política que se caracteriza pela disposição para se submeter a um exame contínuo tudo aquilo que, no presente, se afigura como dado, aceito e naturalizado. Uma disposição que se traduz em "uma certa maneira de pensar, [...] uma certa relação com o que existe, com o que se faz, uma certa relação com a sociedade, com a cultura" (Foucault, 1990). ${ }^{8}$ Em suma, a atitude crítica se revela no embate que o pensamento e o discurso estabelecem constantemente com as artes de governar, o que inclui, evidentemente, as artes pedagógicas enquanto governo dos modos de ser das crianças.

Não se trata-que fique claro - de uma recusa tout courta qualquer forma de governo da conduta. O que a crítica opera é, antes, um exame das alegações e dos dispositivos de governo com o fito de limitá-lo e de nele encontrar a justa medida: "como não ser governado assim, por isso, em nome desses princípios, em vista de tais objetivos e por meios de tais procedimentos..." (1990). . Assim, a crítica emerge ao se pôr em questão - sob o crivo de um pensamento autônomo - a obediência irrefletida a um discurso que se pretende portador de uma verdade que paire acima da pluralidade dos homens e que, nessa qualidade, pretenda legitimar a arte de governar, nos mais variados domínios da vida social.

É importante notar, contudo, que identificação da atitude crítica como uma herança do Esclarecimento não representa em nenhum desses dois pensadores, nem no presente exercício reflexivo - uma adesão irrestrita a seus pressupostos epistemológicos ou históricos, como a noção de uma razão universal ou o caráter teleológico do curso da história. Se recorreremos ao Esclarecimento como marco de um certo tipo de atitude crítica, é por nele enxergar, tal como Foucault, o impulso inicial de um projeto "que não cessa de se formar, de se prolongar, de renascer nos confins da filosofia, sempre próximo dela, sempre contra ela, às suas custas, na direção de uma filosofia por vir...”(1990). ${ }^{10}$

Adotar tal perspectiva implica, pois, pôr em relevo que, a partir do Esclarecimento, a crítica toma a forma de um movimento cultural cuja tarefa nuclear é o desenvolvimento de uma reflexão histórica que examina o passado e vislumbra o futuro como formas de assinalar um 
sentido para suas operações no interior do presente. $\mathrm{E}$ ao assim fazer, funda uma nova tradição de investigações que tem se mostrado diversificada e duradoura. Uma tradição que se atualizará em uma ampla - e muitas vezes conflituosa - gama de tendências filosóficas cujo ponto em comum é a preocupação com questões que se dirigem à elucidação do sentido das experiências do presente; de suas rupturas e continuidades em relação ao passado e de suas expectativas e horizontes em relação ao futuro. Dentre elas, a perspectiva teórica a partir da qual pretendemos levar a cabo este diálogo crítico, que, em termos sintéticos, poderia ser concebida como uma fenomenologia do tempo presente.

O que aqui se pretende apresentar é, pois, um exercício reflexivo acerca de uma experiência do presente que se configura como um desafio comum a professores e legisladores, a teóricos da educação e gestores de políticas públicas: o desafio de eleger princípios e diretrizes curriculares em um mundo que se apresenta simultaneamente globalizado e fragmentado; em um mundo no qual os vínculos culturais com uma comunidade tendem a se desfazer sob o peso de uma ordem produtiva planetária que condena à obsolescência qualquer modo de vida ou prática cultural que a ela não se ajuste, ao mesmo tempo em que, por outro lado, nele ganham força movimentos identitários, sectários e radicais. O desafio é, pois, o de operar escolhas que impliquem uma seleção valorativa de certos aspectos do legado do passado, mas que também veicule expectativas em relação ao futuro; que promova a identificação com um legado de experiências simbólicas comuns a um povo, mas que também seja capaz de abrir-se a um diálogo com outras culturas e modos de vida. E somos compelidos a fazê-lo sem poder contar com o apoio de uma tradição que hierarquize de forma consensual o valor das experiências pregressas ou que forneça critérios compartilhados aos quais poderíamos recorrer para sua legitimação e justificação.

$\mathrm{Na}$ raiz desse problema, reside ainda um fenômeno inquietante e mesmo paradoxal: a constatação de que a universalização da forma escolar como instrumento precípuo de formação educacional se dá em meio à perda - provavelmente irreparável - da tradição, ou seja, da certeza de que um certo legado cultural do passado teria o poder de iluminar as questões e dilemas cruciais do presente e orientar as expectativas em relação ao futuro. Daí o diagnóstico desafiador que Arendt nos apresenta nas conclusões de seu ensaio sobre a crise na educação:

[...] o problema da educação no mundo moderno reside no fato de ela não poder abrir mão, pela peculiaridade de sua natureza, nem da autoridade, nem da tradição; mas mesmo assim ser obrigada a caminhar em um mundo que não é estruturado pela autoridade, nem mantido coeso pela tradição. (Arendt, 1996, p. 235. Tradução nossa). ${ }^{11}$ 
Um diagnóstico que, em certa medida, parece ser compartilhado pelos redatores das DCN quando afirmam que "um dos princípios que orientam as sociedades contemporâneas é a imprevisibilidade. As sociedades abertas não têm os caminhos traçados por um percurso inflexível e estável". ${ }^{12}$ A despeito dessa imagem um tanto caricatural pois a estabilidade de referências simbólicas e de experiências comuns que configuram uma tradição não elimina conflitos de interpretações acerca de seus significados e implicações -, é impossível não reconhecer que o ritmo moderno de transformações técnicas e culturais imprimiu uma crescente instabilidade na relação dos homens com o mundo em que habitam. Se nas sociedades tradicionais os homens se concebiam como "transeuntes" cuja vida escoava em meio a uma paisagem que era percebida como estável e portadora de um sólido legado de sabedoria (Cf. Fourquin, 198), com o advento do "progresso" como modo de vida e representação temporal, o mundo herdado do passado se desfaz diante de seus olhos em um ritmo crescente de aceleração.

Em face de um quadro como esse, que princípios axiológicos poderiam inspirar diretrizes curriculares que sejam, a um só tempo, capazes de conferir inteligibilidade ao mundo e sentido ao percurso que os jovens nele tecem ao longo de suas existências? Sem a estabilidade de uma cultura que se enraíze no tempo, que papel pode ocupar a figura de um professor historicamente identificado com a iniciação de seus alunos em modos de pensamento e de conduta que se encontram inscritos nos próprios padrões e procedimentos das disciplinas e práticas escolares? Estariam esses profissionais destinados a "deixar de ser transmissores de conhecimentos para serem mediadores e facilitadores da aquisição de conhecimentos", ${ }^{13}$ como propõem as DCN? E, se assim o for, em que medida ainda se pode pensar a escola como uma instituição que opera o vínculo entre o passado e o futuro, emprestando durabilidade às realizações históricas de uma cultura? Se "o mundo comum transcende a duração de nossa vida tanto no passado como no futuro", como afirma Arendt, se ele nos vincula "não só com aqueles que vivem conosco, mas também com aqueles que aqui estiveram antes e com aqueles que virão depois de nós", como lhe conferir durabilidade senão pela transmissão intergeracional de um legado de realizações que escolhemos salvar da ruína do tempo que a tudo consome?

Não é nossa intenção apresentar respostas inequívocas a essas questões ou fundamentos últimos para o estabelecimento de critérios de decisão curricular. O que tencionamos levar a cabo, a partir das interrogações afloradas e da perspectiva enunciada, é, em primeiro lugar, a articulação de um conjunto de reflexões acerca dos vínculos 
entre os dilemas e impasses relativos às escolhas curriculares e a natureza peculiar da relação que a nossa sociedade - marcada pelo presentismo como regime dominante de temporalidade ${ }^{14}$ - estabelece com o legado de realizações simbólicas no qual escolhe iniciar seus jovens por meio da educação escolar. Uma escolha que se vê, hoje, obrigada a enfrentar os problemas advindos de uma tensa dialética entre os reclamos de durabilidade de um mundo cujas raízes se encontram no legado de seu passado e um regime de temporalidade marcado pelo fluxo incessante e cada vez mais acelerado de transformações tecnológicas e econômicas que condenam à obsolescência tudo aquilo que não se mostre funcional ao seu próprio ritmo de produção e consumo. Interessa-nos, nesse sentido, pôr em questão alguns dos significados que esses documentos nacionais - e, claro, as perspectivas de educação que os informam e inspiram - atribuem à centralidade dos jovens - mas não do mundo e de suas realizações ! - no estabelecimento de matrizes curriculares. $\mathrm{E}$, por último, interessa-nos analisar criticamente a forma pela qual as DCN concebem a natureza dos compromissos que a escola deve ter para com o princípio da igualdade.

\section{AMOR MUNDI E PHILIA COMO PRINCÍPIOS DAS ESCOLHAS CURRICULARES}

Após aludir de passagem à ruptura da tradição como um elemento subjacente à crise hoje vivida no que concerne à escolha de "matrizes curriculares" e "programas de estudos" para o Ensino Médio, faz-se necessária uma explicação mais detida de sua significação para o campo da educação. Isso porque não é raro que, no domínio discursivo da pedagogia, a noção de "tradição" seja identificada de imediato com o que é da ordem do arcaico ou que seja associada a imagens caricaturais de uma suposta "escola tradicional", dotada de procedimentos metodológicos ultrapassados e de conteúdos rígidos e estanques. Não é essa, evidentemente, a acepção que aqui lhe conferimos.

Em uma densa passagem de seu texto sobre Walter Benjamin, Hannah Arendt sintetiza a complexa relação que a noção de "tradição" estabelece com o passado como fonte de autoridade: "Na medida em que o passado foi transmitido como tradição, possui autoridade; na medida em que a autoridade se apresenta historicamente, converte-se em tradição". ${ }^{15}$ A tradição implica, portanto, um tipo específico de vínculo com o passado, pois the confere autoridade sobre o presente. Um modo de vida fundado na tradição como regime de temporalidade toma acontecimentos e personagens do passado como modelos aos quais se reporta para compreender o presente e iluminar as decisões que se apresentam como necessárias ou desejáveis. 
Esse era o princípio que guiava, por exemplo, a forma pela qual a civilização romana lidava com as narrativas acerca de seu próprio passado. O termo latino traditio - do qual se origina a palavra "tradição" em português - possuía três acepções principais: era o legado de lições transmitidas pelo passado; a grandeza do exemplo dos ancestrais e, finalmente, a própria transmissibilidade desse legado vinculatório às novas gerações que o incorporavam e dele faziam o seu legado (Carvalho, 2017). Daí a noção, tão cara aos romanos, da história como magistra vitae, segundo a qual o passado é concebido como fonte de lições éticas e políticas para o presente. Essa forma de conceber a natureza dos vínculos do presente com o passado foi incorporada pela cultura cristã, que fazia dos Evangelhos e da hagiografia fontes de formação moral, política e religiosa. Para as comunidades cristãs a vida de Jesus de Nazaré é mais do que um evento distante na linha do tempo; é um passado que se faz presente aqui e agora e, assim, dá sentido, rumo e inteligibilidade às existências que nele se desenrolam.

É somente a partir do surgimento e da consolidação da noção moderna de "progresso" que a tradição como regime dominante de temporalidade irá ceder espaço para uma nova forma de se conceber as relações que os homens, em seu presente, estabelecem com o espaço de suas experiências passadas e com o horizonte de expectativas em relação ao futuro. ${ }^{16} \mathrm{O}$ futuro - e não mais o passado - passa, então, a ser considerado como o tempo forte da humanidade. É o caráter teleológico do curso da história - caro a todas as filosofias da história do século XIX - que passa a orientar o sentido das ações do presente, inclusive no plano da formação educacional. Se, para o educador romano Políbio, o sentido da educação era transformar os jovens em pessoas "dignas de seus antepassados", para os modernos o compromisso da educação aponta antes para a construção de uma nova ordem política e social do que para a emulação dos exemplos de seus ancestrais.

Ora, é evidente que uma das consequências dessa transformação no regime dominante de temporalidade será o declínio da tradição como fonte de respostas aos desafios colocados pelo presente. Por isso, para Arendt, a ruptura da tradição desencadeia a emergência de uma crise, concebida não como decadência, mas como um momento em que "perdemos as respostas em que de ordinário nos apoiávamos sem. sequer perceber que elas eram originariamente respostas a questões". ${ }^{17}$ Nesse sentido, afirmar a existência de uma crise no que diz respeito às escolhas de programas de estudo e matrizes curriculares não implica ajuizar a situação do presente como a de um declínio em relação ao passado, mas simplesmente constatar que as certezas que até então nos guiaram (O que ensinar? Como ensinar? Com quais objetivos?) ruíram 
em face das condições e exigências do presente. A crise não é, portanto, decadência, declínio ou ocaso, mas a perda de referenciais seguros, de experiências simbólicas compartilhadas que um dia forneceram critérios comuns para o ajuizamento e a tomada de decisões.

Trata-se de um diagnóstico que, em linhas gerais, não destoa daquele apresentado pelas próprias Diretrizes do Ensino Médio:

A elaboração das Diretrizes Curriculares Nacionais do Ensino Médio se faz necessária [...] em virtude das novas experiências educacionais decorrentes da aceleração da produção do conhecimento, da ampliação do acesso à informação, da criação de novos meios de comunicação, das alterações do mundo do trabalho e das mudanças de interesses dos adolescentes e jovens, sujeitos dessa etapa educacional. ${ }^{18}$

Mas, se os diagnósticos se assemelham, os sentidos atribuídos a essas transformações variam substancialmente. Para os redatores das DCN, trata-se de, em face da crise, "recriar a escola" de forma que ela possa "responder aos desafios colocados pelos jovens"19 e, notese, não pelo mundo! Já em Arendt, a ruptura da tradição - e a crise que ela engendra - não é saudada como progresso, nem lamentada como declínio, mas concebida como um momento decisivo que comporta riscos e oportunidades. Ela tanto pode representar a oportunidade de uma nova relação com o legado do passado, como pode se configurar como um risco que comporta graves consequências, como o de se perder o legado do passado e com ele a dimensão da profundidade que resulta do pertencimento de cada nova geração a um mundo de realizações que a precede no tempo e cuja durabilidade ultrapassa a vida individual de seus membros. Nas palavras de Arendt:

Com a perda da tradição perdemos o fio que nos guiou com segurança pelos vastos domínios do passado, mas esse fio foi também o grilhão que encadeou cada sucessiva geração a um aspecto predeterminado do passado. Poderia ocorrer que somente agora o passado venha a se abrir para nós com inesperado frescor [...]. Mas não se pode negar que, sem uma ancoragem segura da tradição, [...] toda a dimensão do passado fica exposta ao perigo. Estamos ameaçados pelo esquecimento e, um tal olvido - além dos conteúdos que se poderiam perder - significaria que, humanamente falando, nós nos privaríamos de uma dimensão, a dimensão da profundidade na existência humana. Pois memória e profundidade são o mesmo, ou antes, a profundidade só pode ser alcançada pelo homem por meio da recordação. ${ }^{20}$

Não se trata, pois, de cultivar uma nostalgia em relação à firmeza de uma tradição que oferecia critérios e padrões de ajuizamento comuns e mandatórios, nem de saudar o novo como ele se fosse um resultado inexorável do progresso ao qual nos curvamos com resignação ou entusiasmo. Trata-se, antes, de se manter alerta em relação aos potenciais efeitos da crise advinda de sua ruptura. 
Como Arendt assinala em seu ensaio sobre a educação, uma crise não necessariamente se configura como um desastre. Ela pode representar a possibilidade de busca de novas respostas aos desafios que se nos apresentam no presente. E essas respostas podem significar uma liberação em relação às amarras do passado.

Tomemos como exemplo a Lei 10639, de janeiro de 2003, que incluiu o estudo da história da África e da cultura dos povos africanos no Brasil. Ela rompe com uma tradição que, em muitos aspectos, fazia com que a escola brasileira se assemelhasse a uma "escola portuguesa de ultramar", ignorando a presença de um enorme e significativo contingente de povos e culturas na conformação singular do Estado e da nação brasileira. A crise, nesse caso, transformou-se, pela ação política, em uma oportunidade ímpar de lançar um novo olhar para o passado e nele imprimir um inesperado frescor. Em uma oportunidade de "escovar a história a contrapelo", na bela imagem de Benjamin; de abrir novas perspectivas e interpretações para o passado, iluminando acontecimentos ou personagens até então relegados à escuridão e ao esquecimento. A seleção do passado não se desvincula, pois, das inquietações do presente.

Mas a consciência de que a crise pode gerar oportunidades não deve obliterar o fato de que ela também comporta riscos, como o de fomentar um modo de vida - e uma concepção curricular que volte suas costas para os vastos dominios do passado no afã de se conformar ao pragmatismo das demandas do presente travestidas em exigências do futuro. É o que pode ocorrer, por exemplo, ao se propor um currículo centrado exclusiva ou preponderantemente no desenvolvimento de competências e habilidades ${ }^{21}$ supostamente necessárias às demandas econômicas de um imaginado mercado de trabalho por vir, ignorando que a formação humana é consubstancial à compreensão que um sujeito faz de sua inserção num fluxo temporal que se estende tanto em direção ao futuro como ao passado. E que ambas essas dimensões dialogam com seu presente.

Há várias formas pelas quais a obliteração do passado pode ocorrer no âmbito da formação escolar. A recente proposta de eliminação da obrigatoriedade de disciplinas como história, sociologia e filosofia no Ensino Médio ${ }^{22}$ é só o exemplo mais óbvio desse vezo de se obliterar a dimensão temporal do passado e com ele a dimensão de profundidade que uma existência humana só pode adquirir ao se vincular historicamente a uma comunidade cultural. Ora, é evidente que essa dimensão pode ser acessada por várias vias e pelas mais variadas disciplinas ou programas de estudo. Mas, é igualmente evidente que essas, ao lado das artes e da literatura, são 
formas de saber e áreas de conhecimento privilegiadas para o cultivo dessa modalidade de vínculo com o passado a que se refere Arendt. Assim, sua eventual eliminação só pode cooperar para a perda dessa dimensão central da condição humana: a de se compreender como um sujeito cuja constituição é indissociável das densas camadas de temporalidade com as quais ele interage no presente.

Há, contudo, formas mais sutis de se operar esse distanciamento da formação escolar com um legado de experiências simbólicas capazes de conferir um sentido temporal à existência humana. Não são raras, por exemplo, as ocasiões em que as DCN propõem a identidade entre os atos de "educar" e de "cuidar", ressaltando a "centralidade"23 do cuidado em relação ao estudante, retomando, assim, o ideal escolanovista de uma educação centrada nos interesses e características das crianças. O que chama atenção não é, em si, a postulação dessa identidade e nela, do papel central dos sujeitos a quem a educação se dirige. De fato, o ato de educar implica um cuidado e uma atenção constante àqueles que, embora se insiram como sujeitos no processo educacional, são também seu objeto (no sentido gramatical, pois quem educa, educa alguém!). Ocorre que, como nos lembra Arendt, a educação implica um duplo compromisso, no qual o cuidado com os novos (os jovens que adentram um mundo que lhes antecede no tempo) é inseparável do cuidado com o mundo, essa complexa e conflituosa herança histórica de linguagens, práticas, saberes, artefatos, técnicas, princípios que conformam aquilo que Dilthey chamou de Geistige Welt, ou o mundo espiritual de um povo ou uma época.

Talvez em nenhuma outra passagem esse duplo compromisso apareça de forma tão contundente (e poética) como nas palavras que finalizam o ensaio que Arendt escreve sobre a crise na educação:

\footnotetext{
A educação é o ponto em que decidimos se amamos o mundo o bastante para assumirmos a responsabilidade por ele e [...] o salvarmos da ruína que seria inevitável, não fossem a renovação e a vinda dos novos e dos jovens. A educação é também onde decidimos se amamos nossas crianças o bastante para não as expulsar de nosso mundo e abandoná-las a seus próprios recursos, nem tampouco arrancar de suas mãos a oportunidade de empreender alguma coisa nova e imprevista para nós, preparando-as assim para a tarefa de renovar um mundo comum. ${ }^{24}$
}

Note-se que, tanto o amor ao mundo (o amor mundi que Arendt empresta de Agostinho e a ele dá uma nova acepção) como o amor às crianças não devem ser compreendidos como sentimentos pessoais ou íntimos. Eles são, antes, "uma espécie de disposição e de prazer em partilhar discursivamente os acontecimentos mundanos que, ao contrário da compreensão romântica do amor e do amor fraternal, não 
nos remete a nós mesmos, à nossa intimidade e nem nos amalgama coletivamente". ${ }^{25}$ Não se trata, pois, de uma afecção subjetiva, mas de um modo de se relacionar com esse espaço situado "entre-os-homens" que é o mundo comum. Ambos são, portanto, formas complementares de realização da philia, uma espécie de amizade - ou de disposição para com o outro - concebida não como escolha íntima, mas como forma de partilha e pertencimento ao mundo, sempre mediada pela palavra, artifício propriamente humano que confere sentido aos objetos de uma cultura e às experiências que eles nos proporcionam:

Pois o mundo não é humano simplesmente por ter sido feito por seres humanos, e nem se torna humano porque a voz humana nele ressoa. Ele se humaniza apenas quando se tornou objeto de discurso. Por mais afetados que sejamos pelas coisas do mundo, por mais profundamente que elas possam nos instigar e estimular, elas só se tornam humanas para nós quando podemos discuti-las com nossos companheiros. [...] Humanizamos o que ocorre no mundo e em nós mesmos apenas ao falar, e no curso da fala aprendemos a ser humanos. ${ }^{26}$

Daí a importância para educação de um compromisso tanto em relação ao cuidado para com as coisas do mundo - que nos chegam dos vastos domínios do passado - como para com aqueles que nele aportam e formam uma nova geração de companheiros do mundo; tanto do amor mundi como da philia como princípios que presidem o intercâmbio entre as gerações. $\mathrm{O}$ amor ao mundo nos faculta fruir de uma herança de realizações sem a pretensão de possuí-la como um bem privado, enquanto a disposição amical nos possibilita compartilhar discursivamente os objetos materiais e simbólicos do mundo comum com os mais novos, sem a pretensão de formatar seus destinos futuros. Ao familiarizar os jovens com realizações simbólicas do passado, a formação escolar lhes confere a possibilidade de se libertarem das tiranias do presente e se inscreverem, como uma nova geração, em um fluxo temporal que comporta tanto continuidade como ruptura. E é exatamente em benefício daquilo que é novo e revolucionário em cada criança e em cada geração que a educação deve se comprometer com a durabilidade e a conservação do mundo. Não preservando o status quo de uma ordem política e econômica, mas cuidando para que a ruína do tempo não se abata sobre os acontecimentos, personagens, saberes e práticas que escolhemos imortalizar pelo seu ensino. É esse legado simbólico que nos chega do passado que permite, a um só tempo, que cada jovem se constitua como um ser singular na pluralidade do mundo e nele possa fazer eclodir algo de novo, de inesperado ou mesmo de revolucionário. 


\section{A VERIFICAÇÃO DA IGUALDADE COMO COMPROMISSO ESCOLAR}

Em diversas passagens de seu texto, as DCN reiteram a necessidade de a escola "acolher diferentes saberes, manifestações culturais e diferentes óticas" a fim de se constituir como um "espaço de heterogeneidade e pluralidade" de forma que sua ação vise "à superação das desigualdades de natureza sociocultural e socioeconômica". ${ }^{27}$ Não se trata de uma proposta inaudita no panorama pedagógico brasileiro. Ao contrário, a fusão do ideal de acolhimento da diversidade cultural com o objetivo de superação das desigualdades sociais parece ser um elemento cada vez mais recorrente nos discursos e propostas educacionais que visam suplantar a ideia, corrente no discurso liberal conservador, de um currículo universal e de uma meritocracia escolar fundada no talento individual. Trata-se, na verdade, de uma perspectiva que se consolidou, sobretudo, a partir do significativo impacto que a recepção dos estudos culturais e as teses de Bourdieu e Passeron ${ }^{28}$ tiveram no âmbito dos discursos educacionais a partir dos anos 80 .

Desde sua difusão no Brasil, os discursos pedagógicos e as políticas públicas de educação têm procurado explicitar o papel dos fatores extraescolares - como a transformação de uma herança cultural de classe em capital cultural escolarmente rentável - no desempenho dos alunos oriundos de famílias pouco escolarizadas e de baixa renda. O impacto pedagógico desses estudos críticos se cristalizou, grosso modo, em duas vertentes distintas, mas solidárias. Por um lado, ele resultou no surgimento de uma visão cética - ou mesmo niilista - para a qual a identificação da escola com os ideais de emancipação pessoal e de igualdade de oportunidades não passaria de um ardil ideológico cujo verdadeiro objetivo seria dissimular as estruturas de dominação e reprodução de privilégios. Paralelamente - e em alguma medida como resposta a essas tendências - intelectuais e responsáveis por políticas públicas de educação se dedicaram a apresentar justificativas teóricas e propor medidas práticas visando superar ou, ao menos, atenuar os efeitos dessa dinâmica de reprodução das desigualdades. Seus programas de ação passaram, então, a sugerir a necessidade de uma ruptura com os formalismos da cultura escolar e a adoção de um currículo mais adaptado aos alunos oriundos das classes populares.

Ora, a despeito da inegável pertinência de medidas como a abertura do currículo escolar a diferentes manifestações culturais e da relevância política da preocupação com a inclusão e permanência de camadas da população historicamente alijadas da cultura escolar, o os efeitos da recepção pedagógica das teses que proclamam o caráter 
reprodutor do sistema escolar e os resultados das políticas públicas que tomaram como sua tarefa eliminá-lo ou, ao menos atenuá-lo, não têm sido muito auspiciosos. ${ }^{29}$ Por um lado, a convicção de que a escola privilegia os privilegiados parece ter tido entre muitos professores um efeito paradoxal: naturalizou o "fracasso" de seus alunos, atribuindo às suas condições sociais e econômicas as causas de suas supostas dificuldades, transformando, assim, a explicação de um fenômeno social em um destino educacional inexorável. Por outro, a explicitação dos fatores implícitos no êxito escolar dos herdeiros do capital cultural gerou uma corrida para transformar seus habitus e modos específicos de socialização em novos objetos de uma aprendizagem pedagogicamente controlada, agravando, em alguns casos, as desigualdades entre o desempenho de alunos das redes privada e pública.

Mas o que nos interessa nestas reflexões é menos a análise empírica de seus resultados do que o exame das formas pela quais as teorias da reprodução têm sido mobilizadas nas políticas públicas e nos discursos educacionais. Não se trata, pois, de discutir a validade interna de suas conclusões nem a adequação de seus dados empíricos. O que aqui está em questão é algo anterior: a forma pela qual esses discursos concebem e criticam a noção de "democracia" e o ideal republicano da "igualdade", em particular no que concerne à formaescola como instituição privilegiada das mediações entre os indivíduos e a ordem política e socioeconômica.

Em sua obra Às margens da política, Jacques Rancière empreende uma vigorosa crítica a esses discursos - por ele classificados como "ciências da suspeita" - para os quais a não coincidência entre o proclamado e o real e entre as formas democráticas e suas atualizações é tomada como signo inequívoco de uma dominação dissimulada a serviço da perpetuação da desigualdade. É, pois, em resposta a essas correntes da crítica social, permanentemente preocupadas em redescobrir e desvelar a desigualdade como um fato, que Rancière nos instiga a pensar a igualdade não como um produto mensurável que o aparelho estatal oferece à sociedade, mas como um movimento incessante de seus agentes que, através de suas falas e ações, buscam verificá-la e atestá-la, inclusive contrapondo o proclamado ao vivido ou contrastando o princípio à forma presente de sua operacionalização.

A igualdade não é, pois, um fato cuja presença - ou a ausência possa ser empiricamente testada por uma operação cognitiva. Ela não se deixa apreender pela apresentação de estatísticas ou pela mensuração de testes psicométricos que avaliam desempenhos: "liberdade e igualdade, afirma Rancière, são potências que se engendram e crescem por um ato que 
lhes é próprio" (p.71). Essa é a razão pela qual não se pode falar de uma "liberdade" ou de uma igualdade "ilusória": ambas são potências "em relação às quais convém, antes, verificar os efeitos" (2003, p.71). Por essa razão, a virtude da democracia, concebida como espaço de potencial eclosão da verificação da igualdade, não é o estabelecimento de um consenso apaziguador e equalizador, mas a capacidade de reconhecer-se como dessemelhante a si mesma e, por conseguinte, tornarse palco de um trabalho perpétuo de autocorreção:

O homem democrático é um ser de palavra, ou seja, é também um ser poético, capaz de assumir uma distância entre as palavras e as coisas. Uma distância que não significa decepção nem engano, mas antes a capacidade humana de assumir a irrealidade da representação. Uma virtude poética que é também uma virtude de confiança. Trata-se de partir do ponto de vista da igualdade, de afirmá-la, de trabalhar pressupondo-a para ver tudo quanto pode produzir, para maximizar tudo o que se pode dar de liberdade e de igualdade. Quem parte, pelo contrário, da desconfiança; quem parte da desigualdade e se propõe a reduzi-la, hierarquiza as desigualdades, hierarquiza as prioridades, hierarquiza as inteligências e reproduz indefinidamente a desigualdade (Rancière, 2003).

Assim, adotar o ponto de vista da igualdade implica assumir um lugar de partida - ou seja, tomá-lo como um axioma - a partir do qual se fala e se age. Ao estabelecer a igualdade como um destino ao qual se almeja chegar - tal como o fazem as DCN - vemo-nos compelidos a partir da desigualdade, naturalizando-a enquanto princípio, reificando-a como estrutura. Verificar a igualdade - assumindo-a como hipótese prática e não como enunciado passível de falsificação - implica conceber-se como capaz de produzi-la, atualizando uma potencialidade e inscrevendo-a na experiência política. Assim faz Jacotot (Rancière, 1987), o Mestre Ignorante que ousou assumir a igualdade das inteligências como hipótese prática para suas experiências pedagógicas no século XIX. Não lhe interessava hierarquizar as desigualdades de desempenho, nem as comparar a um desempenho ideal previamente estabelecido pelo Mestre. ${ }^{30}$ Ao adotar a igualdade das inteligências como um postulado, interessava-lhe verificar a aptidão de todos para, por si mesmos, aprenderem o que ignoravam, tal como um dia aprenderam sua língua materna. Porque toda obra humana é um ato que atesta sua inteligência. E porque toda obra humana pode ser compreendida por outra inteligência humana. Era esse o sentido que ele conferia à noção de emancipação: uma prova que alguém impõe a si mesmo de se verificar como igualmente capaz; uma prova de que se é efetivamente capaz de pertencer a uma comunidade que partilha objetos simbólicos comuns e dele extrai significados próprios. Uma prova de que somos capazes de efetivamente inscrevermo-nos como iguais na partilha sensível de um mundo comum. 
Analogamente, o potencial igualitário da experiência escolar não reside, para Rancière (2003), em seus possíveis - e sempre incertos - efeitos socioeconômicos posteriores; efeitos que mediriam a igualdade - ou sua ausência - como um fato. Ele se materializa, antes, pela configuração de uma forma que, embora em diálogo com outros domínios da experiência social, adquire nas sociedades contemporâneas um sentido próprio: a criação e a extensão a todos de um tempo livre, ou seja, de um tempo em que não se está submetido às exigências do capital, da produção e da satisfação das necessidades vitais. Um tempo de formação, ou seja, de um aprendizado cuja virtude não é necessariamente capacitar alguém a fazer algo, mas lhe propiciar a oportunidade de se constituir como um sujeito singular; de tornar-se um novo alguém em decorrência das experiências simbólicas que viveu. Um tempo de skholé: a expressão grega que designava um privilégio inicialmente distintivo da aristocracia agrário-militar e que a democracia ateniense converteu em um direito comum a todo e qualquer cidadão.

A transformação da skeholé - à qual a escola moderna, a despeito de inúmeras rupturas, ainda é solidária ${ }^{31}$ - em um direito significou a usurpação de um privilégio em favor de uma experiência de igualdade. Ela operou uma importante disjunção entre nascimento e prestígio social, entre sabedoria e ascendência familiar. Não fosse sua emergência, como explicar a figura de Sócrates, o humilde filho de uma parteira e de um escultor a quem o aristocrático Platão se referia como o mais sábio e justo de todos os atenienses?

Mas não é só nesse sentido que a forma escola, na peculiaridade de sua relação com o tempo representa uma ruptura com a lógica produtiva. Se, por exemplo, nesta última só há lugar para o que se mostra imediatamente útil aos reclamos da produção e do consumo de bens, a escola pode se dar ao luxo de ensinar poesia, filosofia, ciências ou artes, independentemente de qualquer efeito produtivo que esses campos do saber possam vir a ter no transcurso da vida daqueles que neles se iniciam e deles fruem momentaneamente. Por outro lado, ao transformar uma prática social que era restrita a um estamento ou classe em um saber comum e público - como ocorreu com a leitura, a escrita ou a prática do voleibol - a escola materializa seu compromisso com a igualdade, ainda que não controle seus efeitos sobre a distribuição de renda ou a sobre hierarquia dos lugares sociais. Assim, a mera existência de um sistema público de educação - sejam quais forem seus efeitos na distribuição das funções e privilégios sociais e econômicos - torna tangível uma experiência igualitária, ao transformar aqueles que a ele acedem em alunos - ou seja, em pessoas dotadas de um igual direito a um tempo e espaço 
de formação (skholé) -, operando uma equalização dos que ocupam lugares e funções distintas na ordem hierárquica social.

É evidente que a igualdade instituída pela expansão da skholé não constitui a totalidade da igualdade. Mas é igualmente evidente que ela expande a potencialidade da igualdade para um terreno que até então lhe era alheio. O fato de que ela seja virtual não implica, contudo, que ela seja ilusória. Quem confunde o virtual com o ilusório, nos alerta Rancière, se desarma para a tarefa incessante de verificação, atestação e produção da igualdade.

Não se trata, pois, de uma questão de métodos pedagógicos ou renovações curriculares, como querem as DCN, mas de uma visão política e filosófica que informa e subjaz às decisões e práticas educativas. E nesse sentido, tanto a clássica visão de uma escola justa, porque difusora de um saber neutro cujo grau de apreensão dependeria exclusivamente de dons pessoais, quanto as pedagogias ditas progressistas - que pretendem forjar procedimentos e adotar conteúdos que aproximem a escola das camadas desfavorecidas "tomam a igualdade como objetivo, isto é, tomam a desigualdade como ponto de partida". ${ }^{32} \mathrm{O}$ desafio não é, pois, construir a igualdade econômica ou social pela escola, mas adotar a igualdade como princípio potencialmente presente na escola e se dispor a verificá-la nas práticas cotidianas. Pois a igualdade, nos ensina Rancière,

[...] não é nem real, nem formal. Ela não consiste nem no ensino uniforme de crianças da república nem na disponibilidade dos produtos de baixo preço nas estantes de supermercados. A igualdade é fundamental e ausente, ela é atual e intempestiva, sempre dependendo da iniciativa de indivíduos e grupos que, contra o curso natural das coisas, assumem o risco de verificá-la, de inventar as formas, individuais ou coletivas, de sua verificação. ${ }^{33}$

O desafio que se coloca aos profissionais da educação é, pois, o de forjar as condições de possibilidade para que a experiência escolar - a partir da especificidade de suas práticas e dos princípios que a animam - possa se configurar como uma experiência de verificação e atestação da igualdade como potencialidade inscrita no presente, e não como um desígnio a ser realizado em um futuro; como um tempo e um espaço formativo no qual possam emergir práticas que não se concebem como "meios" para se chegar à igualdade, mas como "formas" de emancipar as inteligências para que elas se reconheçam e se enunciem como iguais. Trata-se, pois, de fazer da escola uma potencial experiência de verificaşão da igualdade. 


\section{UMA BREVE NOTA FINAL}

Enquanto problema filosófico, a escolha curricular nos interroga sobre nossas concepções acerca dos vínculos que queremos manter com um legado do passado, com uma promessa de futuro e com os compromissos políticos que assumimos no presente. Já enquanto problema prático e político, ela requer a concordância e a ação de muitos, não a reflexão de um só, exigida pela tessitura de um texto filosófico. E em face dessa exigência incontornável, a filosofia se mostra muitas vezes impotente. Seu traço distintivo é menos a apresentação de um estoque de respostas práticas do que a disposição para interrogar criticamente a experiência. Uma disposição que se inspira na figura daquele que a encarna como prática social: Sócrates, o andarilho loquaz que interroga seus companheiros de mundo desafiando suas concepções acerca de temas como a justiça, a virtude ou a piedade. E ele os interroga não porque tenha as respostas que lhes escapam, mas porque crê que o mero ato de se interrogar - independentemente da eventual formulação de uma resposta - já é um compromisso para com seu aperfeiçoamento enquanto cidadãos. Analogamente, acreditamos que, se a filosofia não é capaz de nos orientar de forma inequívoca acerca das respostas práticas de que necessitamos, ela ao menos pode conferir sentido às lutas cotidianas que nos cabe travar. E o sentido do currículo como forma de se relacionar com o mundo bem pode ser resumido nas palavras com que o poeta T. S. Elliot expressou o duplo compromisso que forja a cultura: "Uma piedade para com os mortos, por mais obscuros que sejam. Uma solicitude para com os que nascerão, por mais distantes que estejam".

\section{REFERÊNCIAS}

AGUIAR, Odílo. A amizade como amor-mundi em Arendt. In: O que nos faz pensar n²8. Rio, PUC, dezembro de 2011.

ARENDT, Hannah. A condição humana. Rio de Janeiro: Forense, 2010.

Between the Past and the Future. New York: Penguin, 1996.

Homens em tempos sombrios. São Paulo: Companhia das Letras, 1997.

Lectures on Kant's Political Philosophy. Chicago: University of Chicago, 1992.

BRASIL, Lei de Diretrizes e B. Lei no 9.394/96, de 20 de dezembro de 1996.

BRASIL. Ministério da Educação. CNE.CEB. Parecer CEB 5 2011.e Resolução 112012 In http: / / portal.mec.gov.br/index.php?option $=$ com_docman\&view $=$ download\&alias $=9915$ pceb005-11-1-1\&Itemid=30192. 
BENJAMIN, W. Magia e técnica, arte e política. São Paulo: Brasiliense, 1989.

BOURDIEU, P. e PASSERON, J. Os herdeiros. Os estudantes e a cultura. São Carlos, UFSC, 2017.

CARVALHO, J.S. F. Educação: uma herança sem testamento. Diálogos com o pensamento de Hannah Arendt. São Paulo: Perspectiva/FAPESP, 2017.

CONSTITUIÇÃO DA REPÚBLICA FEDERATIVA DO BRASIL. Brasília, DF: Senado Federal: Centro Gráfico, 1988. 292 p.

Diretrizes Curriculares Nacionais Gerais da Educação Básica/ Ministério da Educação. Secretaria de Educação Básica. Diretoria de Currículos e Educação Integral. Brasília: MEC, SEB, DICEI, 2013.

FOUCAULT, M. Saber y Verdad. Madrid: La Piqueta, 2010.

O que é a crítica? Qu'est-ce que la critique? Critique et Aufklärung. Bulletin de la Société française de philosophie, Vol. 82, nº 2, pp. 35 - 63, avr/juin 1990 (Conferência proferida em 27 de maio de 1978). Tradução de Gabriela Lafetá Borges e revisão de Wanderson Flor do Nascimento. Disponível em: http://michel-foucault.weebly.com/ uploads/1/3/2/1/13213792/critica.pdf.

FOURQUIN, J. C. Escola e cultura. Porto Alegre: Artmed, 2000.

HARTOG, François. Régimes d'historicité: présentisme et expérience du temps. Paris: Seuil, 2012.

KANT, I. Crítica da Razão Pura. Lisboa: Gulbenkian, 1989

Textos seletos. Petrópolis: Vozes, 1987.

KOSELLECK, R. Futuro Passado. Contribuição à semântica dos tempos históricos. Rio de Janeiro: Contraponto, Editora PUC-RJ, 2006.

LAHIRE, Bernard. La raison scholaire: école et pratiques d'écriture, entre savoir e pouvoir. Rennes: P.U.R., 2008.

LEFORT, C. Écrire à l'épreuve du politique. Paris: Calmann Léry, 1992.

MAASCHELEIN, J. e SIMONS, M. (ed.). Rancière, public education and the taming of democracy. London: Wiley-Blacwell, 2011.

Autêntica, 2012.

Em defesa da escola. Uma questão pública. Belo Horizonte:

RANCIÈRE, Jaques. Le maître ignorant. Paris: Fayard, 1987. (Edição brasileira : Belo Horizonte: Autêntica, 2011. Tradução Lilian do Vale).

Aux bords du politique. Paris: Folio, 2003. Edição argentina: En los bordes de lo politico. Buenos Aires: La Cebra, 2010.

La Mésentente. Paris: Galilée, 1995.

La méthode de l'égalité. Entretien avec Laurent Jeanpierre et Dork Zabunyan. Paris: Bayard (Essais Documents), 2012. 


\section{NOTAS}

1 Diretrizes Curriculares Nacionais Gerais da Educação Básica/ Ministério da Educação. Secretária de Educação Básica. Diretoria de Currículos e Educação Integral. - Brasília: MEC, SEB, DICEI, 2013, p. 7

2 Adotaremos aqui essas expressões escolhidas pelas DCN para se referirem aos componentes curriculares. Cf. DCN, Brasil, 2013, p. 27.

3 Notadamente suas proposições relativas à centralidade dos jovens nos processos educativos e ao compromisso das escolas com a superação das desigualdades socioeconômicas.

4 Kant, I. Crítica da Rąão Pura. Lisboa: Gulbenkian, 1989, p. 5. Grifos nossos.

5 A distinção entre os usos privado e público da razão aparece em seu clássico texto "Resposta à Pergunta: Que é o 'Esclarecimento'?” - nos seguintes termos: “Entendo contudo sob o nome de uso público de sua própria razão aquele que qualquer homem, enquanto sábio, faz dela diante do grande público do mundo letrado” (In: Kant, I. Textos Seletos. Petrópolis: Vozes, 1985. p. 104). Note-se que, a despeito da restrição dos interlocutores àqueles que participam do mundo letrado - decorrência do fato de que o debate que o levou à escrita do artigo se deu em um jornal mensal - Kant atribui a faculdade da sábia rąão a qualquer homem. Não se trata de uma observação marginal neste caso, pois, diferentemente da tradição platônica, Kant tomava a reflexão filosófica como uma faculdade potencialmente acessível a todos os homens e não como um dom restrito a poucos ou como uma especialização profissional. Daí a ênfase na noção de um "uso público" - ou seja, comum a todos - da razão.

6 Kant, 1985, p.102.

7 Arendt, H. Lectures on Kant's Political Philosophy. University of Chicago Press: 1992. p. 40. Tradução nossa.

8 Foucault, M. O que é a crítica? Qu'est-ce que la critique? Critique et Aufklärung. Bulletin de la Société française de philosophie, Vol. 82, nº 2, pp. 35 - 63, avr/juin 1990 (Conferência proferida em 27 de maio de 1978). Tradução de Gabriela Lafetá Borges e revisão de Wanderson Flor do Nascimento. Disponível em: http://michel-foucault.weebly.com/ uploads/1/3/2/1/13213792/critica.pdf.

9 Ibidem, p. 3

10 Ibidem, p.1

11 Arendt, H. Between the past and the future. New York: Penguin, 1996. p. 191. Tradução nossa.

12 Diretrizes Curriculares Nacionais Gerais da Educação Básica/ Ministério da Educação. Secretária de Educação Básica. Diretoria de Currículos e Educação Integral. - Brasília: MEC, SEB, DICEI, 2013, p.14.

13 Cf, DCN p. 165

14 Cf. Harotg, F. Régimes d'bistoricité: présentisme et expérience du temps (Paris: Seuil, 2012). Foi a partir de seu conceito de "regime de historicidade" que forjamos a ideia de um "regime de temporalidade", estendendo as categorias que ele utiliza para além do campo de seu campo original, que é o da historiografia. 
15 Arendt, H. Homens em tempos sombrios. São Paulo: Cia. das Letras, 1987. p. 165

16 Cf. KOSELLECK, R. Futuro Passado. Contribuição à semântica dos tempos históricos. Rio de Janeiro: Contraponto, Editora Puc-RJ, 2006.

17 Arendt, 1996. p. 171. Tradução nossa.

18 DCN. Brasil, 2013, p.146.

19 Ibidem, p. 146

20 Arendt, 1996. p. 94-95

21 "É precisamente no aprender a aprender que deve se centrar o esforço da ação pedagógica", afirmam as DCN em sua página 180. Não obstante a possível pertinência da máxima deweiana no contexto em que foi originalmente enunciada, é forçoso reconhecer que a afirmação específica da escolha de um conteúdo não é desprezível. Podemos, por exemplo, aprender a aprender a ler e interpretar obras literárias tanto a partir de Paulo Coelho como de Guimarães Rosa. Mas, do ponto de vista de uma experiência formativa, a escolha de um ou outro é crucial e muitas vezes alternativa, de forma que refugiar-se em formulações abstratas só elide a gravidade do problema em face do qual temos a responsabilidade de nos posicionar.

22 Cf. PL 6840/2013. http://www.camara.gov.br/proposicoesWeb/fichadetramitacao? idProposicao $=602570$.

23 Cf. DCN, Brasil, 2103, p.13

24 Arendt, 1996, p. 193. Tradução nossa.

25 Aguiar, O. A amizade como amor-mundi em Arendt. In: O que nos faz pensar n²8. Rio, PUC, dezembro de 2011. p. 138.

26 Arendt, 1987, p. 31.

27 DCN, Brasil, 2013, p. 27

28 Cf. Bourdieu, P. e Passeron, J. Os herdeiros. Os estudantes e a cultura. São Carlos, Ufsc, 2017.

29 Vale ressaltar que houve, nas últimas décadas, inegáveis avanços na inclusão e permanência desses segmentos da população nos sistemas escolares brasileiros. No entanto, ao que tudo indica, eles são menos frutos de adaptações curriculares e reformas pedagógicas do que de políticas públicas sociais e econômicas, como a política de quotas no ensino superior e a vinculação do programa bolsa-família à frequência escolar.

30 O termo francês Maître guarda uma multivocidade dificilmente traduzível em português, pois pode se referir a um senhor, cuja contraparte são seus súditos, a um mestre que possui discípulos ou a um professor em relação a seus alunos.

31 Em Sobre a bistória e a teoria da forma escolar, Lahire, Vincent e Thin (2001) criticam as visões que concebem a Paideia grega como uma protoforma da escola moderna. Não obstante, uma das características da forma escolar, tal como por eles concebida, é justamente a cisão entre o aprender e o fazer imediato. Nesse sentido acreditamos que podemos pensar a escola moderna 
como herdeira de alguns princípios da skholé grega, sem com isso postularmos uma continuidade inequívoca entre essas duas instituições sociais que guardam diferenças significativas.

32 Rancière, 2011, p. 14.

33 Ibidem, p. 16.

Submetido: 08/10/2018

Aprovado: 14/02/2019

Contato:

José Sergio Fonseca de Carvalho

Rua Gaicá, no 108

São Paulo $\mid$ SP $\mid$ Brasil

CEP 05.579-070 